\title{
Review Article \\ Physiological Importance of Hydrogen Sulfide: Emerging Potent Neuroprotector and Neuromodulator
}

\author{
Sandesh Panthi, ${ }^{1}$ Hyung-Joo Chung, ${ }^{2}$ Junyang Jung, ${ }^{1,3}$ and Na Young Jeong ${ }^{4}$ \\ ${ }^{1}$ Department of Biomedical Science, Graduate School, Kyung Hee University, No. 26, Kyungheedae-ro, Dongdaemun-gu, \\ Seoul 02447, Republic of Korea \\ ${ }^{2}$ Department of Anesthesiology and Pain Medicine, College of Medicine, Kosin University, No. 262, Gamcheon-ro, Seo-gu, \\ Busan 49267, Republic of Korea \\ ${ }^{3}$ Department of Anatomy and Neurobiology, College of Medicine, Kyung Hee University, No. 26, Kyungheedae-ro, \\ Dongdaemun-gu, Seoul 02447, Republic of Korea \\ ${ }^{4}$ Department of Anatomy and Cell Biology, College of Medicine, Dong-A University, No. 32, Daesingongwon-ro, Seo-gu, \\ Busan 49201, Republic of Korea
}

Correspondence should be addressed to Junyang Jung; jjung@khu.ac.kr and Na Young Jeong; jnyjjy@dau.ac.kr

Received 6 April 2016; Accepted 24 May 2016

Academic Editor: Yanxi Pei

Copyright ( $\odot 2016$ Sandesh Panthi et al. This is an open access article distributed under the Creative Commons Attribution License, which permits unrestricted use, distribution, and reproduction in any medium, provided the original work is properly cited.

Hydrogen sulfide $\left(\mathrm{H}_{2} \mathrm{~S}\right)$ is an emerging neuromodulator that is considered to be a gasotransmitter similar to nitrogen oxide (NO) and carbon monoxide (CO). $\mathrm{H}_{2} \mathrm{~S}$ exerts universal cytoprotective effects and acts as a defense mechanism in organisms ranging from bacteria to mammals. It is produced by the enzymes cystathionine $\beta$-synthase (CBS), cystathionine $\Upsilon$-lyase (CSE), 3-mercaptopyruvate sulfurtransferase (MST), and D-amino acid oxidase (DAO), which are also involved in tissue-specific biochemical pathways for $\mathrm{H}_{2} \mathrm{~S}$ production in the human body. $\mathrm{H}_{2} \mathrm{~S}$ exerts a wide range of pathological and physiological functions in the human body, from endocrine system and cellular longevity to hepatic protection and kidney function. Previous studies have shown that $\mathrm{H}_{2} \mathrm{~S}$ plays important roles in peripheral nerve regeneration and degeneration and has significant value during Schwann cell dedifferentiation and proliferation but it is also associated with axonal degradation and the remyelination of Schwann cells. To date, physiological and toxic levels of $\mathrm{H}_{2} \mathrm{~S}$ in the human body remain unclear and most of the mechanisms of action underlying the effects of $\mathrm{H}_{2} \mathrm{~S}$ have yet to be fully elucidated. The primary purpose of this review was to provide an overview of the role of $\mathrm{H}_{2} \mathrm{~S}$ in the human body and to describe its beneficial effects.

\section{Introduction}

Hydrogen sulfide $\left(\mathrm{H}_{2} \mathrm{~S}\right)$ is a poisonous gas that is a toxicant in most organs in the human body. It acts as a gaseous signaling molecule and chemical reagent involved in many physiological processes, including the pathogeneses of various diseases such as neurodegenerative disease, heart failure, and diabetes $[1,2]$. As a result, the beneficial roles of this compound were neglected for many years due to its toxic nature. However, in recent years, the benefits of gasotransmitters such as nitric oxide (NO) and carbon monoxide (CO) have acted as a fillip to investigating the benefits of $\mathrm{H}_{2} \mathrm{~S}$ [3]. Furthermore, a reevaluation of the endogenous levels of $\mathrm{H}_{2} \mathrm{~S}$ confirmed its existence and advantages in mammalian tissues [4].
$\mathrm{H}_{2} \mathrm{~S}$ is a sulfur analog of water and, due to its weak intermolecular force, exists in a gaseous form that is colorless but has an offensive odor [5]. At a pH of 7.4 in the mammalian body, one-fifth of the total $\mathrm{H}_{2} \mathrm{~S}$ subsists in an undissociated form, with the remaining content existing as hydrosulfide anions $\left(\mathrm{HS}^{-}\right)$and sulfide $\left(\mathrm{S}^{2-}\right)$. The high lipid solubility of $\mathrm{H}_{2} \mathrm{~S}$ allows it to easily penetrate the plasma membrane of cells in its undissociated form [6] but it remains unclear whether this undissociated form is physiologically pertinent [7]. Various studies performed on rat, human, and bovine brain tissues have determined that $\mathrm{H}_{2} \mathrm{~S}$ is present at levels of up to $50-160 \mu \mathrm{mol} / \mathrm{L}$ in tissues and that sodium hydrogen sulfide (NaHS) is one of the physiological donors of $\mathrm{H}_{2} \mathrm{~S}$ [8]. 
Although it is known that $\mathrm{H}_{2} \mathrm{~S}$ protects nerves from oxidative stress, saves photoreceptor cells in the retina from light-induced degeneration, regulates endoplasmic reticulum stress, and defends the kidneys from ischemic reperfusion injury [9], the role of $\mathrm{H}_{2} \mathrm{~S}$ in the central nervous system (CNS) has attracted a lot of attention over the past few decades. The neuromodulation and neuroprotection of nerve cells are a common feature of $\mathrm{H}_{2} \mathrm{~S}$ [9] and its enzymes exert effects in a variety of diseases such as Parkinson's disease (PD), Alzheimer's disease (AD), Down's syndrome, cerebral ischemia, and Huntington's disease [10, 11]. Additionally, following injury in the peripheral nervous system (PNS), peripheral nerves undergo Wallerian degeneration and macrophages are recruited into the distal nerve pump [12]. The regeneration of these injured peripheral nerves is associated with the demyelination, dedifferentiation, and proliferation of Schwann cells, which takes place serially. Recently, the possible involvement of $\mathrm{H}_{2} \mathrm{~S}$ in demyelinating disorders and nerve degenerative disorders has also been suggested $[13,14]$.

Thus, the present review focuses on the physiological roles of $\mathrm{H}_{2} \mathrm{~S}$ in different systems and organs, including the CNS, and in peripheral nerve degeneration and regeneration. A consensus regarding findings in these areas will aid in the determination of appropriate avenues for $\mathrm{H}_{2} \mathrm{~S}$ in research investigating neural regeneration and the treatment of neurodegenerative diseases and may lead to potential therapeutic strategies that employ $\mathrm{H}_{2} \mathrm{~S}$.

\section{Biosynthesis of $\mathrm{H}_{2} \mathrm{~S}$}

Two pyridoxal-5' ${ }^{\prime}$-phosphate- (PLP-) dependent enzymes present in mammalian tissues, cystathionine $\beta$-synthase (CBS; EC 4.2.1.22) and cystathionine $\Upsilon$-lyase (CSE; EC 4.4.1.1), are primarily responsible for the biosynthesis of $\mathrm{H}_{2} \mathrm{~S}$ from L-cysteine (L-Cys) $[15,16] . \mathrm{H}_{2} \mathrm{~S}$ can be produced by other pathways as well. Cysteine first reacts with ketoacids to form 3-mercaptopyruvate via the catalytic action of cysteine aminotransferase (CAT; EC 2.6.1.3) and then 3-mercaptopyruvate is desulfurated by 3-mercaptopyruvate sulfurtransferase (MST; EC 2.8.1.2) to form $\mathrm{H}_{2} \mathrm{~S}$ [17]. $\mathrm{H}_{2} \mathrm{~S}$ is mostly synthesized by cystathionase in the liver, kidneys, enterocytes, and vascular smooth muscle cells, by CBS in the brain, and by MST in cardiac tissues [18]. Recently, it was reported that dihydrolipoic acid (DHLA) and thioredoxin are the endogenous reducing substances that cause MST to release $\mathrm{H}_{2} \mathrm{~S}$ [16] and that CBS is the catalytic agent responsible for the condensations of cysteine and homocysteine, which produces $\mathrm{H}_{2} \mathrm{~S}$ and cystathionine via a $\beta$-replacement reaction $[19,20]$. The distributions of CBS and CSE in mammalian tissue are different. A cardiovascular study determined that CSE plays a major role in producing $\mathrm{H}_{2} \mathrm{~S}$ under normal physiological conditions [21] while another study found that the MST pathway mainly contributes to its production in the brain and that this pathway is regulated by intracellular calcium $\left(\mathrm{Ca}^{2+}\right)$ in a concentration-dependent manner $[16,22,23]$.

A recent study used Western blot and immunohistochemistry analyses to investigate DAO expression and methylene blue assays to assess $\mathrm{H}_{2} \mathrm{~S}$ biosynthesis and revealed that
$\mathrm{H}_{2} \mathrm{~S}$ is also produced from $\mathrm{D}$-cysteine via the enzyme Damino acid oxidase (DAO) [24]. The $\mathrm{H}_{2} \mathrm{~S}$ production pathway that uses $\mathrm{D}$-cysteine primarily operates in the cerebellum and kidney and, thus, was termed the DAO/MST pathway $[25,26]$. Although DAO is confined to peroxisomes and MST is located in the mitochondria, these factors exchange numerous enzymes and metabolites [16]; these findings provide strong support for calling this pathway the DAO/MST pathway. Interestingly, the production of $\mathrm{H}_{2} \mathrm{~S}$ via DAO is subdued by indole-2-carboxylic acid but this effect was not seen with MST [26]. A nonenzymatic pathway for the production of $\mathrm{H}_{2} \mathrm{~S}$ also exists and involves the reduction of elemental sulfur to $\mathrm{H}_{2} \mathrm{~S}$ by reducing equivalents procured via the oxidation of glucose [27]. Either hyperglycemia or the escalation of oxidative stress conditions can nurture the production of $\mathrm{H}_{2} \mathrm{~S}$ via this nonenzymatic route in mammalian erythrocytes [8]. The endogenous production and metabolism of $\mathrm{H}_{2} \mathrm{~S}$ and its aforementioned biosynthetic and transformation pathways are illustrated in Figure 1.

It is believed that two possible mechanisms can explain the release of $\mathrm{H}_{2} \mathrm{~S}$. First, after its production, $\mathrm{H}_{2} \mathrm{~S}$ may be liberated by the enzymes involved in its synthesis and, second, $\mathrm{H}_{2} \mathrm{~S}$ may be stored and released in response to physiological needs in mammalian tissue [28]. $\mathrm{H}_{2} \mathrm{~S}$ is released from acidliable sulfur (sulfur atom in iron-sulfur complex) under acidic conditions, while under alkaline conditions bound sulfane-sulfur comes into play; the favorable $\mathrm{pH}$ range for its release under these conditions is approximately 5.4 and 8.4, respectively [29]. The discovery of the DAO/MST pathway suggests that additional $\mathrm{H}_{2} \mathrm{~S}$ biosynthetic pathways may be revealed in the future.

\section{Interrelationships with Other Gasotransmitters}

Although $\mathrm{H}_{2} \mathrm{~S}, \mathrm{NO}$, and $\mathrm{CO}$ have similar molecular targets and cellular actions, these compounds also have a tendency to compete with each other. For example, the gasotransmitters $\mathrm{CO}$ and NO have particular relationships with CBS [8]. After the initial demonstration of the physiological roles of $\mathrm{H}_{2} \mathrm{~S}$ in 1996 [31], it took 5 more years to determine that NO can bind to CBS and can impede enzymatic activity and that CBS has a high affinity for $\mathrm{CO}$ [32]. However, the exact mechanisms underlying these relationships remain unknown. $\mathrm{NO}$ also modulates the endogenous production of $\mathrm{H}_{2} \mathrm{~S}$ in smooth muscle cells and vessels [33]. Previously, it was thought that the signaling pathways and functional mechanisms associated with $\mathrm{H}_{2} \mathrm{~S}$ and $\mathrm{NO}$ were autonomous, but their combined effects on angiogenesis and vasorelaxation have complicated this issue for researchers. If endothelial NO synthase (eNOS) is blocked, then it fully rescinds the angiogenic effects of $\mathrm{H}_{2} \mathrm{~S}$ whereas the silencing of $\mathrm{H}_{2} \mathrm{~S}$ significantly attenuates the angiogenic effects of $\mathrm{NO}$ [34]. Additionally, both $\mathrm{H}_{2} \mathrm{~S}$ and NO activate protein kinase $\mathrm{G}$, as well as its cellular signaling, and 1-H-[1,2,4] oxadiazolo[4-3,-a] quinoxalin-1-one (ODQ), which is a soluble guanylyl cyclase inhibitor that decreases both $\mathrm{H}_{2} \mathrm{~S}$ - and $\mathrm{NO}$-induced angiogenesis [35].

Under severe conditions such as heart inflammation and heart failure events, $\mathrm{H}_{2} \mathrm{~S}$ and $\mathrm{NO}$ cooperate and communicate 


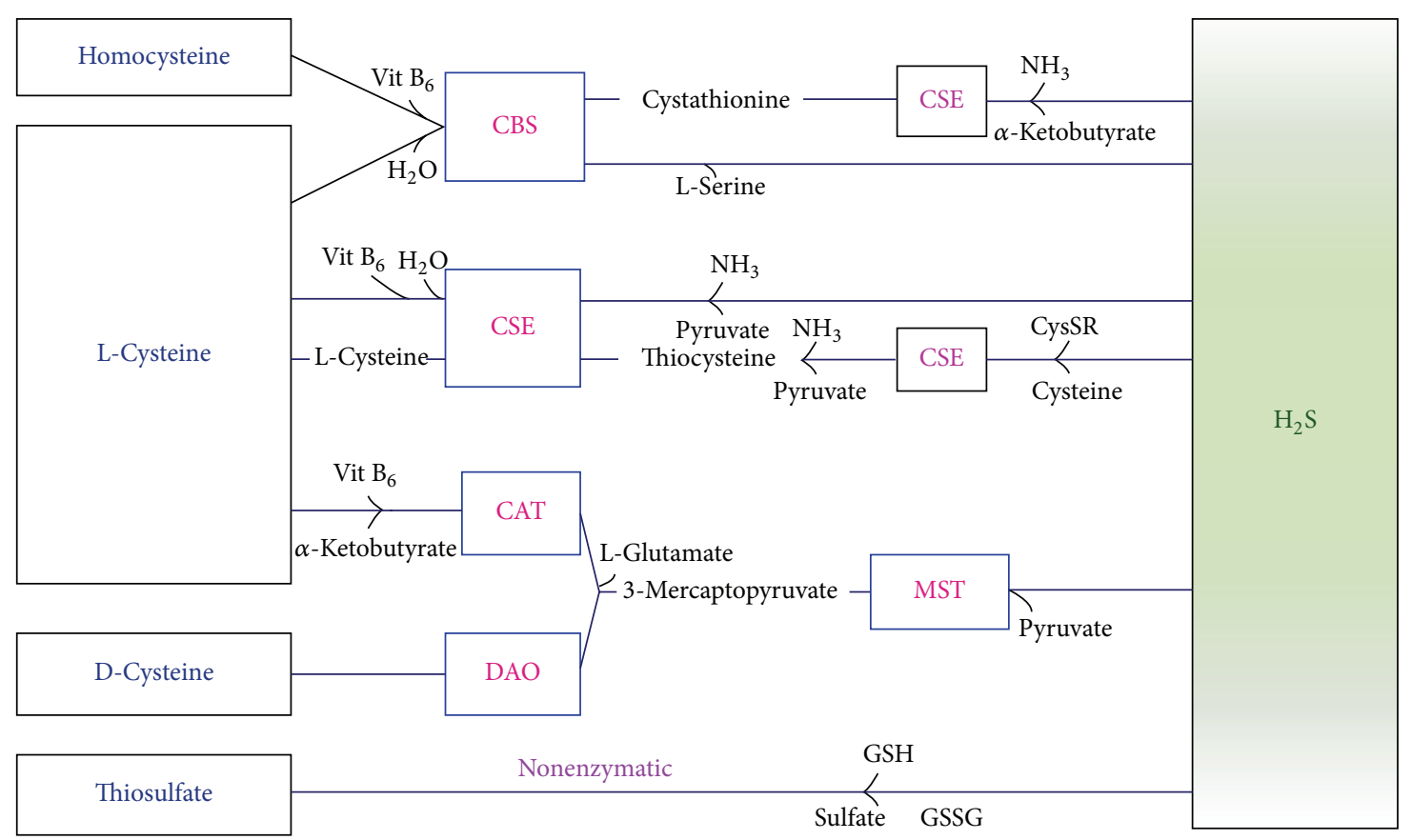

FIGURE 1: Biosynthetic pathways and the transformation of $\mathrm{H}_{2} \mathrm{~S}$ in the mammalian body. $\mathrm{H}_{2} \mathrm{~S}$ is synthesized in the mammalian body via both enzymatic and nonenzymatic pathways but the nonenzymatic pathway accounts for only a small portion of its production. CBS and CSE both use PLP and vitamin $\mathrm{B}_{6}$ as cofactors. In the presence of cysteine and more so in the presence of homocysteine, CBS catalyzes the production of $\mathrm{H}_{2} \mathrm{~S}$, and the condensations of homocysteine and serine are the most recognized reactions catalyzed by CBS. CSE uses L-cysteine as the substrate to form two gases, $\mathrm{H}_{2} \mathrm{~S}$ and $\mathrm{NH}_{3}$, as well as pyruvate. MST and CAT produce $\mathrm{H}_{2} \mathrm{~S}$ and pyruvate from 3-mercaptopyruvate, which is formed from L- or D-cysteine, and $\alpha$-ketoglutarate, which is produced by CAT. Thiosulfate nonenzymatically produces $\mathrm{H}_{2} \mathrm{~S}$ and all essential components of this nonenzymatic path are present in vivo. Thiosulfate can be converted into sulfite in the liver, kidney, or brain tissues via thiosulfate reductase or by thiosulfate sulfurtransferase in the liver. $\mathrm{H}_{2} \mathrm{~S}$ is also released from thiosulfate and persulfides [8, 30].

with each other to stimulate thiol-sensitive compounds that produce unambiguous positive outcomes for inotropic and lusitropic heart abnormalities [36]. Ex vivo aortic explants of wild-type and CSE-knockout (CSE-KO) mice were used to explore the possible interaction between $\mathrm{H}_{2} \mathrm{~S}$ and $\mathrm{NO}$ and revealed that CSE-KO mice exhibit a significant decrease in vascular neogenesis [37]. The authors also proposed that the interaction of these gasotransmitters stimulates endothelial cell proliferation. The administration of $\mathrm{H}_{2} \mathrm{~S}$ to rats with clinical symptoms of hypoxic pulmonary hypertension has also been shown to increase plasma CO concentrations [38]. $\mathrm{CO}$ and $\mathrm{H}_{2} \mathrm{~S}$ act on the same target but have opposite patterns of outcome. For example, coevoked channel activation is completely suppressed by potassium cyanide $(\mathrm{KCN} ; 1 \mathrm{mM})$ but there are no consequences during $\mathrm{H}_{2} \mathrm{~S}$-induced channel activation [39]. Thus, the precise nature of the relationship between these gasotransmitters in various physiological pathways remains unclear and requires further investigation. However, even if $\mathrm{H}_{2} \mathrm{~S}, \mathrm{NO}$, and $\mathrm{CO}$ compete with each other, their interactions are likely to result in beneficial effects on mammalian physiology.

\section{Effect of $\mathrm{H}_{2} \mathrm{~S}$ on the CNS}

$\mathrm{H}_{2} \mathrm{~S}$ has a proven neuromodulatory role in the protection of neurons from oxidative stress, as evidenced by its inhibition of hypochlorous acid-mediated oxidative damage [40] and
$\mathrm{ONOO}^{-}$-mediated protein nitration and cytotoxicity [41] in neuroblastoma cells. Recent studies have also established that $\mathrm{H}_{2} \mathrm{~S}$ plays an important role in the upregulation of the GABA $\beta$-receptor at both pre- and postsynaptic sites [42]. Astrocytes and microglial cells play important roles in the regulation of brain $\mathrm{pH}$ levels, neurotransmitter levels, and neuronal excitability [43] while microglia are also associated with the progression of neuronal diseases such as AD [44] and $\mathrm{PD}[45] . \mathrm{H}_{2} \mathrm{~S}$ evokes $\mathrm{Ca}^{2+}$ waves in astrocytes that trigger $\mathrm{a} \mathrm{Ca}^{2+}$ influx via its channels in the plasma membrane [7] and also reversibly increases $\mathrm{Ca}^{2+}$ levels in microglia in a dosedependent manner [46].

In addition to regulating $\mathrm{Ca}^{2+}$ homeostasis, $\mathrm{H}_{2} \mathrm{~S}$ may also be involved in long-term potentiation (LTP) and the modulation of various neurotransmitters [5]. $\mathrm{H}_{2} \mathrm{~S}$ facilitates hippocampal LTP via the activation of $\mathrm{N}$-methyl-D-aspartate (NMDA) receptors as well as the phosphorylation of these receptors by protein kinase A (PKA) [47] and regulates intracellular $\mathrm{Ca}^{2+}$ level in astrocytes and hippocampal slices [10]. $\mathrm{H}_{2} \mathrm{~S}$ also safeguards neurons by controlling endoplasmic stress via the balancing of membrane potentials and the activation of $\mathrm{K}_{\mathrm{ATP}}$ and cystic fibrosis transmembrane conductance regulator chloride (CFTR $\mathrm{Cl}^{-}$) channels [9]. Most neurons in the nucleus solitarius, which are believed to play a role in the cardiovascular system, are depolarized by $\mathrm{H}_{2} \mathrm{~S}$ [48]. Additionally, a donor of $\mathrm{H}_{2} \mathrm{~S}, \mathrm{NaHS}$, is linked to 
the inhibition of apoptosis, decreases of edema in the brain, and the amelioration of cognitive dysfunction, which could attenuate early brain injury development due to subarachnoid hemorrhage via several mechanisms [49]. The major roles and possible therapeutic targets of $\mathrm{H}_{2} \mathrm{~S}$ are illustrated in Figure 2.

Thus, it can be concluded that $\mathrm{H}_{2} \mathrm{~S}$ exerts protective and modulatory effects on nerve cells, either cooperatively or independently. Although the physical and chemical properties of $\mathrm{H}_{2} \mathrm{~S}$ remain elusive, its roles in these processes have become more clearly defined and most of its mechanisms of action are understood.

4.1. $\mathrm{H}_{2} \mathrm{~S}$ and $\mathrm{PD}$. PD is primarily characterized by cognitive deficiencies resulting from changes in the nucleus basalis of Meynert and the cerebral cortex and the continuous loss of dopaminergic neurons in the mesencephalon [50]. $\mathrm{H}_{2} \mathrm{~S}$ inhibits oxygen consumption and 6-OHDA-evoked nicotinamide adenine dinucleotide phosphate (NADPH) oxidation and activates microglial cells in the midbrain which, in turn, lead to the accumulation of proinflammatory factors in the subcortical part of the forebrain [51]. This is the primary mechanism by which $\mathrm{H}_{2} \mathrm{~S}$ decreases the chances of further neuronal injury and degeneration [52]. The neuroprotective role of $\mathrm{H}_{2} \mathrm{~S}$ has also been demonstrated in experimental rat models of neurotoxin-induced PD [50]. The advantageous effects of $\mathrm{H}_{2} \mathrm{~S}$ are due to its activation or suppression of different protein kinases, such as PKC, PI3K/Akt, p38, JNK, and the ERK-MAPKs [53], which decrease oxidative stress and inflammation and exert antiapoptotic actions.

Although L-Dopa is the most commonly used drug for the treatment of $\mathrm{PD}$ due to its ability to maintain dopamine levels, it cannot block or reverse the progression of PD. Additionally, long-term L-Dopa therapy may lead to neurodegeneration [54] and dyskinesia [55] in and of itself. $\mathrm{H}_{2} \mathrm{~S}$ stimulates glutamate transporter functioning and leads to direct sulfa hydration via the ERK/MAPK pathway, which attenuates the production of reactive oxygen species and decreases oxidative stress $[56,57]$. Thus, it can be concluded that L-Dopa and $\mathrm{H}_{2} \mathrm{~S}$ may be more effective for the treatment of PD when used in combination. A mouse model of PD constructed using 1-methyl-4-phenyl-1,2,3,6,-tetrahydropyridine (MPTP) plus probenecid injections results in the destruction of dopaminergic neurons but the administration of $\mathrm{H}_{2} \mathrm{~S}$ increases the survival rate of neurons and is protective against MPTP-induced toxicity [58]. Thus, $\mathrm{H}_{2} \mathrm{~S}$ not only protects peripheral tissues but also effectively treats neurological damage related to PD. Recently, it was shown that drinking coffee and inhaling cigarettes can inhibit monoamine oxidase (MAO) [59], which suggests that there is a lower risk of PD in coffee drinkers and smokers. Cakmak found that coffee contains Prevotella-derived $\mathrm{H}_{2} \mathrm{~S}$ and that $\mathrm{H}_{2} \mathrm{~S}$ is a welldocumented constituent of cigarette smoke.

4.2. $\mathrm{H}_{2} \mathrm{~S}$ and $A D$. $\mathrm{AD}$, which is one of the most familiar types of dementia, is caused by activated microglia and increases in neuritic plaques carrying the $\beta$-amyloid protein [60]. This neurodegenerative disease has been exhaustively researched because it affects the cortex and hippocampus and leads to severe cognitive dysfunction [61]. The etiology of $\mathrm{AD}$ is multifactorial and presumably includes a number of distinctive etiopathogenic mechanisms [62]. CBS is thought to be the main source of $\mathrm{H}_{2} \mathrm{~S}$ in the brain. In 1996, it was first shown that S-adenosylmethionine, which is a CBS activator, is significantly reduced in subjects with $\mathrm{AD}$ [63]. Moreover, the severity of $\mathrm{AD}$ is related to altered levels of $\mathrm{H}_{2} \mathrm{~S}$ [64] because the pathological state of $\mathrm{AD}$ in the human body has been associated with lower levels of endogenous $\mathrm{H}_{2} \mathrm{~S}$ and the accumulation of homocysteine in the brain $[65,66]$. Several series of in vitro and in vivo experiments demonstrated the role of $\mathrm{H}_{2} \mathrm{~S}$ in the promotion of cell growth and preservation of mitochondrial function [67] as well as in the retardation of oxidative stress factors such as amyloid beta peptides $(\mathrm{A} \beta)$, malondialdehyde (MDA), hypochlorite (HOCI), and 4hydroxy-2-nonenal (4-HNE) $[68,69]$. In adult male Wistar rats without serious signs of $\mathrm{H}_{2} \mathrm{~S}$ toxicity, spa water with excessive amounts of $\mathrm{H}_{2} \mathrm{~S}$ has the ability to improve cognitive processes by decreasing A $\beta$ deposits and targeting the APP, PST, and ON/4R-tau isoforms [70]. Additionally, NaHS, which is a donor of $\mathrm{H}_{2} \mathrm{~S}$, retards protein oxidation and lipid peroxidation in the neuroblastoma cells of $\mathrm{AD}$ patients [71].

Cerebral atrophy, seizures, and intellectual disabilities can be caused by the autooxidation of homocysteine [72, 73] and hyperhomocysteinemia has been identified in brains of $\mathrm{AD}$ patients [74]. $\mathrm{H}_{2} \mathrm{~S}$ protects against and reduces homocysteine-induced toxicity and oxidative stress through its antioxidant properties in the adrenal medulla (PC12 cells) and vascular smooth muscle cells of rats $[75,76]$. Synaptic dysfunction and vascular inflammation are also believed to play crucial roles in the pathogenesis of $\mathrm{AD}$ [77]. Recent analyses of the expressions of mRNA and synaptic proteins in C57BL/6J wild-type male mice clearly demonstrated that plasma homocysteine-induced alterations in learning and memory processes were associated with synaptic remodeling in the hippocampus [78]. Thus, $\mathrm{H}_{2} \mathrm{~S}$ can influence synaptic remodeling. Vascular dementia (VD) is another common neurodegenerative disorder that, much like $\mathrm{AD}$, is caused by cerebral ischemia. $\mathrm{H}_{2} \mathrm{~S}$ modulates oscillatory coupling in the hippocampus and may represent a possible molecular mechanism underlying the changes in VD patients [79].

Although neurodegenerative pathologies like $\mathrm{AD}$ and PD do not initially involve inflammation, various experimental findings suggest that the inflammatory responses of macrophages, microglia, and astrocytes contribute to the progressions of both diseases [14]. The relevance of the CBS, CSE, MST, and CAT enzymes in the development of AD and $\mathrm{PD}$ is still unexplained and direct evidence supporting the potential advantages of $\mathrm{H}_{2} \mathrm{~S}$ as a therapeutic strategy for these diseases is unavailable.

4.3. Other CNS Diseases. Various experimental studies have correlated the effects of $\mathrm{H}_{2} \mathrm{~S}$ in different pathological states of the human body. Ischemic stroke increases tissue levels of $\mathrm{H}_{2} \mathrm{~S}$ in the cerebral cortex [80] while $\mathrm{H}_{2} \mathrm{~S}$ has been shown to protect the embryonic brain against ischemiareperfusion injury [81]. A rat model of febrile seizure is associated with elevated plasma levels of $\mathrm{H}_{2} \mathrm{~S}$, and Down's syndrome is known to cause the overaccumulation of $\mathrm{H}_{2} \mathrm{~S}$ 


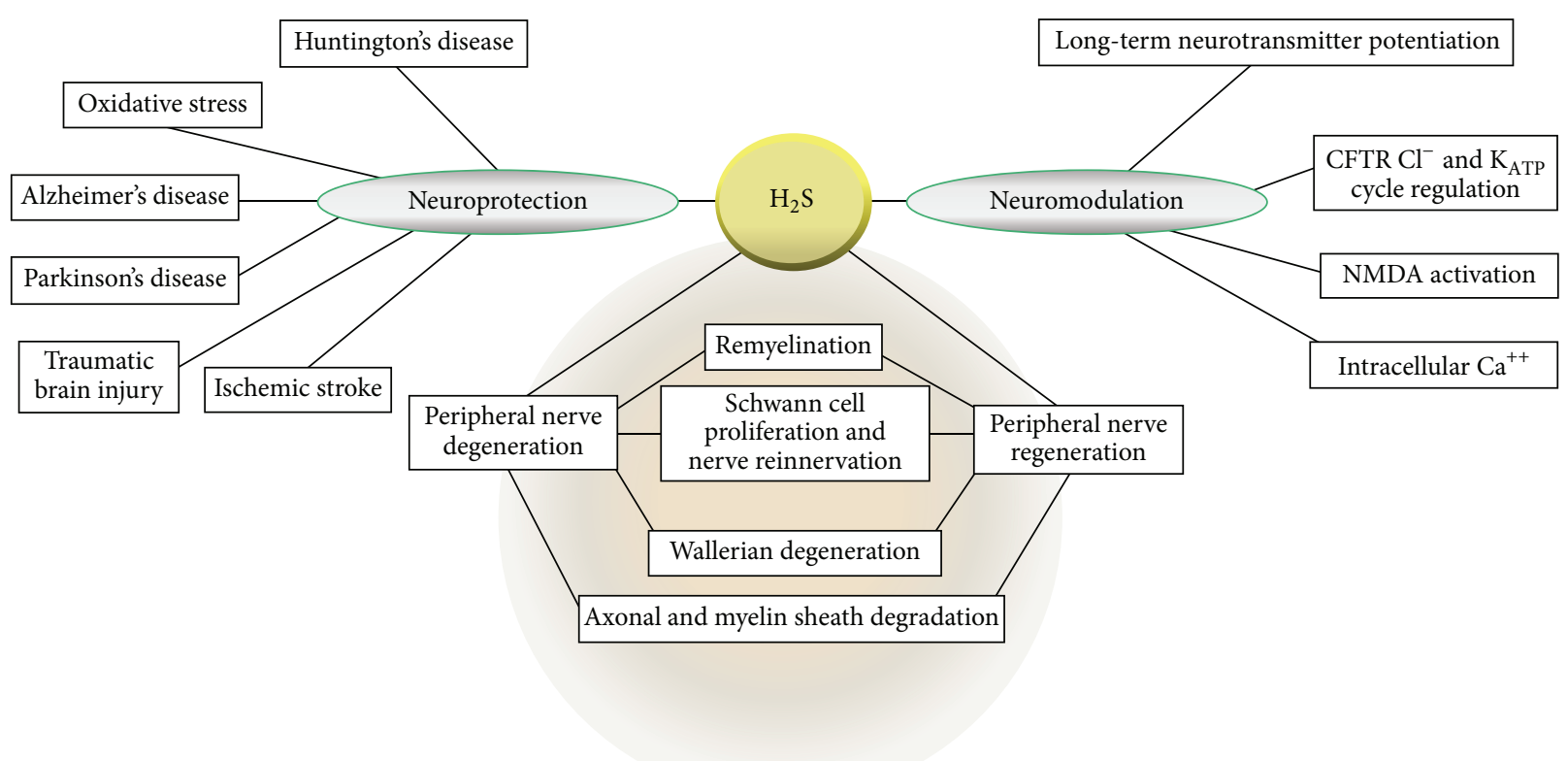

FIGURE 2: Therapeutic targets and possible physiological functions of $\mathrm{H}_{2} \mathrm{~S}$. Enough experimental evidence has been collected to prove the prominent role of $\mathrm{H}_{2} \mathrm{~S}$ in normal pathophysiology. Therefore, many therapeutic targets exist for $\mathrm{H}_{2} \mathrm{~S}$ in mammalian body; its roles in neuroprotection, neuromodulation, and antiproliferation, as well as its functions during peripheral nerve degeneration and regeneration, are widely appreciated.

in the brain [42]. Similarly, there are increased total plasma homocysteine levels in patients with Huntington's disease and CBS deficiencies lead to homocystinuria [50]. Additionally, $\mathrm{H}_{2} \mathrm{~S}$ reverses learning and memory problems caused by damage to the hippocampus $[82,83]$.

\section{5. $\mathrm{H}_{2} \mathrm{~S}$ and the PNS}

Even if the most important roles that glial cells play involve the physical and metabolic support of neurons via the maintenance of the extracellular environment, these support cells are often referred to as "glial culprits" because the CNS lacks the ability to regenerate itself, even after injury [84]. On the other hand, Schwann cells in the PNS are best known for their roles in supporting nerve regeneration, conducting nerve impulses along axons, and modulating neuromuscular synaptic activity and nerve development [85]. The possible roles of $\mathrm{H}_{2} \mathrm{~S}$ in peripheral nerve degeneration and regeneration are discussed below and supported with experimental evidence.

5.1. $\mathrm{H}_{2} \mathrm{~S}$ in Peripheral Nerve Degeneration. Based on the degrees of damage in the nerve and surrounding connective tissue, peripheral nerve damage may be classified as neurapraxia, axonotmesis, and neurotmesis, with the latter being a severe type of peripheral nerve injury [86]. As stated above, nerve regeneration after injury is possible in the PNS and involves major events such as Wallerian degeneration, axonal degeneration, remyelination, axonal regeneration, and nerve reinnervation. $\mathrm{H}_{2} \mathrm{~S}$ plays vital roles throughout this process. Axonal regeneration and remyelination begin in the distal pump of injured peripheral nerves and involve axonal degeneration and the degradation of the myelin sheath of Schwann cells, which is termed Wallerian degeneration [87].

The effects of $\mathrm{H}_{2} \mathrm{~S}$ on peripheral nerve degeneration and regeneration may be best explained by recent ex vivo experiments using the sciatic nerves of mice. In these experiments, Park et al. [12] utilized N-ethylmaleimide (NEM), which is an inhibitor of all cysteine peptidases, to inhibit the production of $\mathrm{H}_{2} \mathrm{~S}$ during Wallerian degeneration and found that NEM inhibits not only CSE but also the basal expression of MST. Based on analyses of several markers of Schwann cell dedifferentiation and proliferation, these authors concluded that $\mathrm{H}_{2} \mathrm{~S}$ signaling has great value after peripheral nerve injury regarding myelin fragmentation, axonal degradation, and Schwann cell dedifferentiation and proliferation. Additionally, these findings demonstrated that $\mathrm{H}_{2} \mathrm{~S}$ production influences transcriptional regulation in Schwann cells during Wallerian degeneration. A similar study inhibited these processes via NEM or through several Schwan cell dedifferentiation or immaturity markers including lysosomal associated membrane protein 1 (LAMP1), neurotrophin receptor $\mathrm{p} 75\left(\mathrm{p} 75^{\mathrm{NTR}}\right)$, the protein coded by JUN gene (c-jun), and phospho-ERK 1/2 (p-ERK1/2) [15]. Jung and Jeong found that these types of inhibition decreased myelin ovoid fragmentation, axonal degeneration, and Schwann cell dedifferentiation, demyelination, and proliferation through neurotrophin receptors, the MAPK pathway, lysosomal protein degradation, and transcriptional regulation.

The use of these markers in current research has garnered much attention. For example, the LAMP1 marker is related to the degeneration of peripheral nerves, including the nonuniform morphology of myelinated axons, in aged individuals [88]. The function of $\mathrm{p} 75^{\mathrm{NTR}}$ is associated not only 
with cell death and survival but also with the maintenance of axonal elongation and the release of neurotransmitters between sympathetic neurons and cardiac myocytes [89]. Furthermore, the reexpression of $\mathrm{p} 75^{\mathrm{NTR}}$ has been identified in various pathological scenarios, including neurodegenerative disorders [90]. Due to its roles as a protein and a component of a transcription factor, the inactivation of $\mathrm{c}$ jun in mice resulted in delays and/or the failure to properly complete the regeneration procedure and an enhancement of neuronal death [91]. Although the molecular pathways are not yet fully understood, the absence of c-jun causes the complete downregulation of neurotrophic genes such as artemin (Artn), brain-derived neurotrophic factor 1 (BDNF1), glial cell-derived neurotrophic factor (GDNF), leukemia inhibitory factor (LIF), and nerve growth factor (NGF). These findings suggest that neurotrophins may be a potential target for the treatment of various neuropathies. Studies of the molecular mechanisms involved in those processes explained above have revealed the capability of Schwann cells to regenerate axons and to rescue motor neurons following nerve injury [92].

However, many issues relevant to this process remain unexplained, including the relationships between neurotrophic factors and $\mathrm{H}_{2} \mathrm{~S}, \mathrm{H}_{2} \mathrm{~S}$ production, and remyelination that is associated with the extracellular matrix (ECM) protein, as well as intracellular regulators, hormones, and transcriptional regulators that involve $\mathrm{H}_{2} \mathrm{~S}$ [15]. Other than $\mathrm{H}_{2} \mathrm{~S}$, the ubiquitin proteasome system (UPS) is another factor that is essential for the regenerative functions of peripheral nerves after injury $[93,94]$.

5.2. $\mathrm{H}_{2} \mathrm{~S}$ in Peripheral Nerve Regeneration. Other issues associated with the role of $\mathrm{H}_{2} \mathrm{~S}$ in peripheral nerve regeneration involve the responses of Schwann cells in $\mathrm{H}_{2} \mathrm{~S}$ production. Schwann cells are believed to be an important factor in the regeneration process because peripheral axons have no function as $\mathrm{H}_{2} \mathrm{~S}$ producers during Wallerian degeneration [12]. Nerve injury leads to the dedifferentiation of Schwann cells from myelinated cells to immature undeveloped cells [15] and, as discussed in Section 5.1, decreases in $\mathrm{H}_{2} \mathrm{~S}$ production attenuate changes in markers of dedifferentiation. Thus, it is important that reductions in $\mathrm{H}_{2} \mathrm{~S}$ production nurture both the regeneration of axons and the remyelination during the last stage of Wallerian degeneration. Immature undeveloped Schwann cells undergo multiplication and reach the target, injured organ, which is when the possible beneficial effects of $\mathrm{H}_{2} \mathrm{~S}$ come into play. Remyelination is another important process involved in nerve regeneration whereby Schwann cells are able to flourish due to myelination and the inhibition of $\mathrm{H}_{2} \mathrm{~S}$ production (via transcriptional regulation through krox20 and c-jun), which is fundamental to this stage of regeneration [15].

Despite the above findings, very few studies have attempted to analyze the roles that $\mathrm{H}_{2} \mathrm{~S}$ plays in peripheral nerve degeneration and regeneration. Although our research group is currently conducting studies to identify the core effects of $\mathrm{H}_{2} \mathrm{~S}$, the existing literature strongly supports the importance of $\mathrm{H}_{2} \mathrm{~S}$ in nerve degeneration and regeneration.

\section{Other Functions of $\mathrm{H}_{2} \mathrm{~S}$}

The exciting evolution of $\mathrm{H}_{2} \mathrm{~S}$ in the field of neuroscience has revealed its importance not only in the PNS but also in various physiological and pathological conditions. For example, endogenous levels of $\mathrm{H}_{2} \mathrm{~S}$ have been shown to influence exogenous $\mathrm{H}_{2} \mathrm{~S}$ during cell apoptosis [95]. Additionally, the antiproliferative and proapoptotic effects of $\mathrm{H}_{2} \mathrm{~S}$ have a significant influence on various disorders such as vascular graft occlusion, atherosclerosis, and neointimal hyperplasia [96]. $\mathrm{H}_{2} \mathrm{~S}$ also regulates glutathione levels by enhancing the hustle of the cysteine/glutamate antiporter at the cellular level, which directly neutralizes free radicals and reactive oxygen compounds and balances the levels of vitamins $\mathrm{C}$ and $\mathrm{E}$ in their reduced form [97]. The acute inhalation of $\mathrm{H}_{2} \mathrm{~S}$ protects lungs from injuries induced by ventilators and relaxes pulmonary vascular tissue but epidemiological data suggest that the long-term exposure to even low levels of $\mathrm{H}_{2} \mathrm{~S}$ can cause bronchial hyperresponsiveness [8].

Relative to other parts of the body, the gastrointestinal tract (GIT) contains the largest amount of $\mathrm{H}_{2} \mathrm{~S}$, where it subsidizes the homeostatic control of GIT mucosal defenses and repairs damage [31]. However, the signaling pathways of $\mathrm{H}_{2} \mathrm{~S}$ in the GIT remain unclear. Other beneficial effects of $\mathrm{H}_{2} \mathrm{~S}$ on translation and transcription include the control of endoplasmic reticulum stress and activating the unfolding protein response. During these processes, CSE increases $\mathrm{H}_{2} \mathrm{~S}$ production and ultimately restores endoplasmic reticulum homeostasis via the sulfa hydration reaction [98]. Additionally, type 1 diabetes is believed to involve the overproduction of $\mathrm{H}_{2} \mathrm{~S}$ [18], and $\mathrm{H}_{2} \mathrm{~S}$ may be helpful for patients with erectile dysfunction due to its involvement in the relaxation of the smooth muscle that causes the erection of the penis [99]. Recently, six fatal cases of $\mathrm{H}_{2} \mathrm{~S}$ poisoning were reported during an attempt to unblock a wastewater cistern in which the primary reason for death was $\mathrm{H}_{2} \mathrm{~S}$ aspiration and because it is a mediator and regulator of various physiological conditions, $\mathrm{H}_{2} \mathrm{~S}$ can have serious toxic effects [100].

The roles of $\mathrm{H}_{2} \mathrm{~S}$ in insulin resistance syndrome and regional ischemic damage, as well as its dose-dependent relationship with methylglyoxal (MG) in vascular smooth muscle cells, also require explanation [3]. Because it is an antioxidant bulwark, $\mathrm{H}_{2} \mathrm{~S}$ has the capacity to sense chromaffin cells and chemoreceptors [101] but it has yet to be determined how $\mathrm{H}_{2} \mathrm{~S}$ increases local blood perfusion and/or ventilation [102]. Further justification is needed for the production of $\mathrm{H}_{2} \mathrm{~S}$ via MST under physiological conditions because this process requires full alkaline conditions [103].

\section{Therapeutic Prospect and Potential of $\mathrm{H}_{2} \mathrm{~S}$}

Almost two decades of research on $\mathrm{H}_{2} \mathrm{~S}$ unfastened series of positive outcomes and its potential is expanding every day. Molecular mechanisms of $\mathrm{H}_{2} \mathrm{~S}$ are being uncovered and various types of molecular and sulfa hydration targets are on the phase of identification which may lead us to reveal its biological activities [10]. Several in vivo and in vitro studies on $\mathrm{AD}$ and $\mathrm{PD}$ model have already proved their therapeutic effectiveness for treatment [40, 68, 104, 105]. 
Surprisingly, inhaled $\mathrm{H}_{2} \mathrm{~S}$ has found to have protective effect against neuropathic pain and brain edema which has also made researchers think seriously in this topic because we can develop our opinion and research arena on hydrogen sulfide donor compounds against neuropathic pain and brain edema [106, 107]. Even though $\mathrm{H}_{2} \mathrm{~S}$ has to deal with its own double face (toxic and protective) attitude which has pushed it into several controversies, it is recently found that various ion channels in multiple systems and organs advocate the protective role of $\mathrm{H}_{2} \mathrm{~S}$ [108]. Because of the overall effect, $\mathrm{H}_{2} \mathrm{~S}$-releasing drugs are now under clinical trial after their verified effectiveness in animal model. This trend of clinical trial on finding $\mathrm{H}_{2} \mathrm{~S}$ donors or $\mathrm{H}_{2} \mathrm{~S}$-releasing drugs can be a very big breakthrough for the treatment of several diseases which are almost incurable till date [109]. $\mathrm{H}_{2} \mathrm{~S}$-releasing derivatives of mesalamine [110] and diclofenac [111] have already been shown to decrease inflammatory disease and gastric hemorrhagic lesions compared to original drugs and some possibility for the treatment of injured brain after subarachnoid hemorrhage $(\mathrm{SAH})$ via $\mathrm{H}_{2} \mathrm{~S}$ is also a great progress [112] because another study demonstrated that it reduces the level of reactive oxygen species and lipid peroxides malondialdehyde following SAH [113]. Recent studies on the effect of $\mathrm{H}_{2} \mathrm{~S}$ on brain synaptic remodeling and its role in GABA-mediated and glutamate neurotransmission have even increased its prospective potential in physiological standpoint [114]. Even with the difference between community and industry based results, the effect of environmental exposure to $\mathrm{H}_{2} \mathrm{~S}$ on $\mathrm{CNS}$ has exposed its novel and diverse role [115]. Neuroprotective role of $\mathrm{H}_{2} \mathrm{~S}$ after traumatic brain injury has also proven its potentiality and efficacy for other CNS related diseases [116]. Thus, it can be summarized that future prospect of $\mathrm{H}_{2} \mathrm{~S}$ in development of new therapeutic strategy is wide and bright.

\section{Concluding Remarks}

An adequate amount of evidence has been gathered in support of $\mathrm{H}_{2} \mathrm{~S}$ as a gasotransmitter and modulator in mammalian tissue, particularly in the nervous system. $\mathrm{H}_{2} \mathrm{~S}$ is principally produced in the liver, kidney, enterocytes, and vascular smooth muscle cells via cystathionase and partially produced in cardiac tissue by MST. It is catabolized in mitochondria by thiosulfate reductase, and thiosulfate in the urine may be used as a marker of $\mathrm{H}_{2} \mathrm{~S}$ biosynthesis. $\mathrm{H}_{2} \mathrm{~S}$ is capable of both suppressing and promoting inflammation but it remains unclear how these proinflammatory and anti-inflammatory activities can be enhanced or attenuated. The role of $\mathrm{H}_{2} \mathrm{~S}$ in the Schwann cell response to peripheral nerve injury has been well established by experimental evidence, and the importance of $\mathrm{H}_{2} \mathrm{~S}$ signaling during Wallerian degeneration, where it broadly affects Schwann cell dedifferentiation and proliferation, has been repeatedly demonstrated.

The bidirectional relationship between $\mathrm{H}_{2} \mathrm{~S}$ and $\mathrm{NO}$ is another area of particular research interest and therapeutic potential. Experimental studies using inhibitors or donors of endogenous $\mathrm{H}_{2} \mathrm{~S}$ have produced clear evidence of its effects but clinical studies that can define its role in the treatment of diseases are necessary. Pharmaceutical companies should accelerate their attempts to formulate, design, and produce $\mathrm{H}_{2} \mathrm{~S}$-releasing drugs with sustained/controlled release functions as they are likely to be highly innovative for the treatment of neurodegenerative diseases. Thus, therapeutic prospects of $\mathrm{H}_{2} \mathrm{~S}$ signaling for patients with neurodegenerative disease and demyelination disorders are imminent. However, the uncontrollable release, unidentified byproducts, and unclear mechanisms of release and action represent major issues related to the research and clinical use of $\mathrm{H}_{2} \mathrm{~S}$. Although it is currently a time of great interest and excitement regarding the potential of $\mathrm{H}_{2} \mathrm{~S}$ in medicine and biology, many hypotheses regarding $\mathrm{H}_{2} \mathrm{~S}$ have yet to be supported and many issues remain unanswered. Even though various novel molecular targets have been identified and research is hastily expanding, biomedical research into this gasotransmitter is still in its initial stages.

\section{Competing Interests}

The authors reported no potential conflict of interests.

\section{Authors' Contributions}

Sandesh Panthi and Hyung-Joo Chung contributed equally to this work.

\section{Acknowledgments}

This study was supported by Basic Science Research Program through the Korean National Research Foundation (NRF) funded by the Ministry of Science, ICT and Future Planning (Professor Junyang Jung, 2015R1A2A2A01002735; Professor Na Young Jeong, 2015R1C1A1A02036863). The authors would like to thank Sangya Gyawali (University of Pittsburgh, USA) for her valuable help and suggestions.

\section{References}

[1] K. Kashfi and K. R. Olson, "Biology and therapeutic potential of hydrogen sulfide and hydrogen sulfide-releasing chimeras," Biochemical Pharmacology, vol. 85, no. 5, pp. 689-703, 2013.

[2] K. M. Holwerda, S. A. Karumanchi, and A. T. Lely, "Hydrogen sulfide: role in vascular physiology and pathology," Current Opinion in Nephrology and Hypertension, vol. 24, no. 2, pp. 170176, 2015.

[3] R. Wang, "Hydrogen sulfide: the third gasotransmitter in biology and medicine," Antioxidants \& Redox Signaling, vol. 12, no. 9, pp. 1061-1064, 2010.

[4] J. Furne, A. Saeed, and M. D. Levitt, "Whole tissue hydrogen sulfide concentrations are orders of magnitude lower than presently accepted values," American Journal of PhysiologyRegulatory Integrative and Comparative Physiology, vol. 295, no. 5, pp. R1479-R1485, 2008.

[5] K. Qu, S. W. Lee, J. S. Bian, C.-M. Low, and P. T.-H. Wong, "Hydrogen sulfide: neurochemistry and neurobiology," Neurochemistry International, vol. 52, no. 1-2, pp. 155-165, 2008. 
[6] E. Cuevasanta, A. Denicola, B. Alvarez, and M. N. Möller, "Solubility and permeation of hydrogen sulfide in lipid membranes," PLoS ONE, vol. 7, no. 4, Article ID e34562, 2012.

[7] H. Kimura, "Production and physiological effects of hydrogen sulfide," Antioxidants and Redox Signaling, vol. 20, no. 5, pp. 783-793, 2014.

[8] R. Wang, "Physiological implications of hydrogen sulfide: a whiff exploration that blossomed," Physiological Reviews, vol. 92, no. 2, pp. 791-896, 2012.

[9] H. Kimura, "Physiological role of hydrogen sulfide and polysulfide in the central nervous system," Neurochemistry International, vol. 63, no. 5, pp. 492-497, 2013.

[10] X. Zhang and J.-S. Bian, "Hydrogen sulfide: a neuromodulator and neuroprotectant in the central nervous system," ACS Chemical Neuroscience, vol. 5, no. 10, pp. 876-883, 2014.

[11] S. Gheibi, N. Aboutaleb, M. Khaksari et al., "Hydrogen sulfide protects the brain against ischemic reperfusion injury in a transient model of focal cerebral ischemia," Journal of Molecular Neuroscience, vol. 54, no. 2, pp. 264-270, 2014.

[12] B. S. Park, H.-W. Kim, I. J. Rhyu et al., "Hydrogen sulfide is essential for Schwann cell responses to peripheral nerve injury," Journal of Neurochemistry, vol. 132, no. 2, pp. 230-242, 2015.

[13] Q.-H. Gong, X.-R. Shi, Z.-Y. Hong, L.-L. Pan, X.-H. Liu, and Y.-Z. Zhu, "A new hope for neurodegeneration: possible role of hydrogen sulfide," Journal of Alzheimer's Disease, vol. 24, supplement 2, pp. 173-182, 2011.

[14] P. K. Moore and M. Whiteman, Chemistry, Biochemistry and Pharmacology of Hydrogen Sulfide, Springer, Berlin, Germany, 2015.

[15] J. Y. Jung and N. Y. Jeong, "Hydrogen sulfide controls peripheral nerve degeneration and regeneration: a novel therapeutic strategy for peripheral demyelinating disorders or nerve degenerative diseases," Neural Regeneration Research, vol. 9, no. 24, pp. 2119-2121, 2014.

[16] Y. Mikami, N. Shibuya, Y. Kimura, N. Nagahara, Y. Ogasawara, and H. Kimura, "Thioredoxin and dihydrolipoic acid are required for 3-mercaptopyruvate sulfurtransferase to produce hydrogen sulfide," Biochemical Journal, vol. 439, no. 3, pp. 479485, 2011.

[17] D. Julian, J. L. Statile, S. E. Wohlgemuth, and A. J. Arp, "Enzymatic hydrogen sulfide production in marine invertebrate tissues," Comparative Biochemistry and Physiology, Part AMolecular and Integrative Physiology, vol. 133, no. 1, pp. 105-115, 2002.

[18] P. Kamoun, " $\mathrm{H}_{2} \mathrm{~S}$, un nouveau neuromodulateur," Médecine/Sciences, vol. 20, no. 6-7, pp. 697-700, 2004.

[19] X. Chen, K.-H. Jhee, and W. D. Kruger, "Production of the neuromodulator $\mathrm{H}_{2} \mathrm{~S}$ by cystathionine $\beta$-synthase via the condensation of cysteine and homocysteine," The Journal of Biological Chemistry, vol. 279, no. 50, pp. 52082-52086, 2004.

[20] O. Kabil, V. Vitvitsky, P. Xie, and R. Banerjee, “The quantitative significance of the transsulfuration enzymes for $\mathrm{H}_{2} \mathrm{~S}$ production in murine tissues," Antioxidants \& Redox Signaling, vol. 15, no. 2, pp. 363-372, 2011.

[21] L. L. Pan, X. H. Liu, Q. H. Gong, H. B. Yang, and Y. Z. Zhu, "Role of cystathionine $\gamma$-Lyase/hydrogen sulfide pathway in cardiovascular disease: a novel therapeutic strategy?" Antioxidants \& Redox Signaling, vol. 17, no. 1, pp. 106-118, 2012.

[22] N. Shibuya, M. Tanaka, M. Yoshida et al., "3-Mercaptopyruvate sulfurtransferase produces hydrogen sulfide and bound sulfane sulfur in the brain," Antioxidants and Redox Signaling, vol. 11, no. 4, pp. 703-714, 2009.
[23] M. Ishigami, K. Hiraki, K. Umemura, Y. Ogasawara, K. Ishii, and H. Kimura, "A source of hydrogen sulfide and a mechanism of its release in the brain," Antioxidants and Redox Signaling, vol. 11, no. 2, pp. 205-214, 2009.

[24] S. Tang, D. Huang, N. An, D. Chen, and D. Zhao, "A novel pathway for the production of $\mathrm{H}_{2} \mathrm{~S}$ by DAO in rat jejunum," Neurogastroenterology \& Motility, vol. 28, no. 5, pp. 687-692, 2016.

[25] N. Shibuya, S. Koike, M. Tanaka et al., "P33 A novel pathway for the production of hydrogen sulfide from $\mathrm{D}$-cysteine in mammalian cells," Nitric Oxide, vol. 39, supplement, article S26, 2014.

[26] N. Shibuya, S. Koike, M. Tanaka et al., "A novel pathway for the production of hydrogen sulfide from D-cysteine in mammalian cells," Nature Communications, vol. 4, article 1366, 2013.

[27] G. A. Aboalsamh, "Mitochondria-Targeted Hydrogen Sulphide Donors Protect Renal Cells From Hypoxia Re-Oxygenation Injury," Electronic Thesis and Dissertation Repository, Paper 2912, 2015.

[28] H. Zhang, P. Wang, G. Chen, H.-Y. Cheung, and H. Sun, "A highly sensitive fluorescent probe for imaging hydrogen sulfide in living cells," Tetrahedron Letters, vol. 54, no. 36, pp. 48264829, 2013.

[29] H. Kimura, "Hydrogen sulfide: its production, release and functions," Amino Acids, vol. 41, no. 1, pp. 113-121, 2011.

[30] M. S. Vandiver and S. H. Snyder, "Hydrogen sulfide: a gasotransmitter of clinical relevance," Journal of Molecular Medicine, vol. 90, no. 3, pp. 255-263, 2012.

[31] K. Abe and H. Kimura, "The possible role of hydrogen sulfide as an endogenous neuromodulator," The Journal of Neuroscience, vol. 16, no. 3, pp. 1066-1071, 1996.

[32] S. Taoka and R. Banerjee, "Characterization of NO binding to human cystathionine $\beta$-synthase: possible implications of the effects of CO and NO binding to the human enzyme," Journal of Inorganic Biochemistry, vol. 87, no. 4, pp. 245-251, 2001.

[33] W. Zhao, J. Zhang, Y. Lu, and R. Wang, "The vasorelaxant effect of $\mathrm{H}_{2} \mathrm{~S}$ as a novel endogenous gaseous $\mathrm{K}_{A T P}$ channel opener," The EMBO Journal, vol. 20, no. 21, pp. 6008-6016, 2001.

[34] J. Bełtowski and A. Jamroz-Wiśnniewska, "Hydrogen sulfide and endothelium-dependent vasorelaxation," Molecules, vol. 19, no. 12, pp. 21506-21528, 2014.

[35] C. Coletta, A. Papapetropoulos, K. Erdelyi et al., "Hydrogen sulfide and nitric oxide are mutually dependent in the regulation of angiogenesis and endothelium-dependent vasorelaxation," Proceedings of the National Academy of Sciences of the United States of America, vol. 109, no. 23, pp. 9161-9166, 2012.

[36] Q.-C. Yong, J. L. Cheong, F. Hua et al., "Regulation of heart function by endogenous gaseous mediators-crosstalk between nitric oxide and hydrogen sulfide," Antioxidants and Redox Signaling, vol. 14, no. 11, pp. 2081-2091, 2011.

[37] Z. Altaany, G. Yang, and R. Wang, "Crosstalk between hydrogen sulfide and nitric oxide in endothelial cells," Journal of Cellular and Molecular Medicine, vol. 17, no. 7, pp. 879-888, 2013.

[38] D. J. Polhemus and D. J. Lefer, "Emergence of hydrogen sulfide as an endogenous gaseous signaling molecule in cardiovascular disease," Circulation Research, vol. 114, no. 4, pp. 730-737, 2014.

[39] V. Telezhkin, S. P. Brazier, S. Cayzac, C. T. Müller, D. Riccardi, and P. J. Kemp, "Hydrogen sulfide inhibits human BKCa channels," in Arterial Chemoreceptors, pp. 65-72, Springer, New York, NY, USA, 2009. 
[40] M. Whiteman, N. S. Cheung, Y.-Z. Zhu et al., "Hydrogen sulphide: a novel inhibitor of hypochlorous acid-mediated oxidative damage in the brain?" Biochemical and Biophysical Research Communications, vol. 326, no. 4, pp. 794-798, 2005.

[41] M. Whiteman, J. S. Armstrong, S. H. Chu et al., "The novel neuromodulator hydrogen sulfide: an endogenous peroxynitrite 'scavenger'?" Journal of Neurochemistry, vol. 90, no. 3, pp. $765-768,2004$

[42] Y. Han, J. Qin, X. Chang, Z. Yang, D. Bu, and J. Du, "Modulating effect of hydrogen sulfide on gamma-aminobutyric acid B receptor in recurrent febrile seizures in rats," Neuroscience Research, vol. 53, no. 2, pp. 216-219, 2005.

[43] R. C. Koehler, D. Gebremedhin, and D. R. Harder, "Role of astrocytes in cerebrovascular regulation," Journal of Applied Physiology, vol. 100, no. 1, pp. 307-317, 2006.

[44] M. Wojtera, B. Sikorska, T. Sobow, and P. P. Liberski, "Microglial cells in neurodegenerative disorders," Folia Neuropathologica, vol. 43, no. 4, pp. 311-321, 2005.

[45] Y. S. Kim and T. H. Joh, "Microglia, major player in the brain inflammation: their roles in the pathogenesis of Parkinson's disease," Experimental and Molecular Medicine, vol. 38, no. 4, pp. 333-347, 2006.

[46] S. W. Lee, Y.-S. Hu, L.-F. Hu et al., "Hydrogen sulphide regulates calcium homeostasis in microglial cells," Glia, vol. 54, no. 2, pp. 116-124, 2006.

[47] J.-F. Wang, Y. Li, J.-N. Song, and H.-G. Pang, "Role of hydrogen sulfide in secondary neuronal injury," Neurochemistry International, vol. 64, no. 1, pp. 37-47, 2014.

[48] R. Malik and A. V. Ferguson, "Hydrogen sulfide depolarizes neurons in the nucleus of the solitary tract of the rat," Brain Research, vol. 1633, pp. 1-9, 2016.

[49] T. Li, H. Liu, H. Xue et al., "Neuroprotective effects of hydrogen sulfide against early brain injury and secondary cognitive deficits following subarachnoid hemorrhage," Brain Pathology, 2016.

[50] L.-F. Hu, M. Lu, C. X. Tiong, G. S. Dawe, G. Hu, and J.-S. Bian, "Neuroprotective effects of hydrogen sulfide on Parkinson's disease rat models," Aging Cell, vol. 9, no. 2, pp. 135-146, 2010.

[51] A. D. Korczyn, "Vascular contribution to dementia in Parkinson's disease," Neurodegenerative Diseases, vol. 7, no. 1-3, pp. 127-130, 2010.

[52] L.-F. Hu, M. Lu, P. T. Hon Wong, and J.-S. Bian, "Hydrogen sulfide: neurophysiology and neuropathology," Antioxidants and Redox Signaling, vol. 15, no. 2, pp. 405-419, 2011.

[53] C. X. Tiong, M. Lu, and J.-S. Bian, "Protective effect of hydrogen sulphide against 6-OHDA-induced cell injury in $\mathrm{SH}$ SY5Y cells involves PKC/PI3K/Akt pathway," British Journal of Pharmacology, vol. 161, no. 2, pp. 467-480, 2010.

[54] N. Hattoria, M. Wanga, H. Taka et al., "Toxic effects of dopamine metabolism in Parkinson's disease," Parkinsonism and Related Disorders, vol. 15, no. 1, pp. S35-S38, 2009.

[55] J. Jankovic and M. Stacy, "Medical management of levodopaassociated motor complications in patients with Parkinson's disease," CNS Drugs, vol. 21, no. 8, pp. 677-692, 2007.

[56] M. Lu, L.-F. Hu, G. Hu, and J.-S. Bian, "Hydrogen sulfide protects astrocytes against $\mathrm{H}_{2} \mathrm{O}_{2}$-induced neural injury via enhancing glutamate uptake," Free Radical Biology and Medicine, vol. 45, no. 12, pp. 1705-1713, 2008.

[57] X. Xue and J.-S. Bian, "Neuroprotective effects of hydrogen sulfide in Parkinson's disease animal models: methods and protocols," Methods in Enzymology, vol. 554, pp. 169-186, 2015.
[58] M. Wang, J. Zhu, Y. Pan et al., "Hydrogen sulfide functions as a neuromodulator to regulate striatal neurotransmission in a mouse model of Parkinson's disease," Journal of Neuroscience Research, vol. 93, no. 3, pp. 487-494, 2015.

[59] Y. O. Cakmak, “Coffee consumption, smoking, and Parkinson's disease? The beneficial role of hydrogen sulfide," Movement Disorders, vol. 31, no. 3, p. 429, 2016.

[60] H. Hampel, "Amyloid- $\beta$ and cognition in aging and Alzheimer's disease: molecular and neurophysiological mechanisms," Journal of Alzheimer's Disease, vol. 33, no. 1, pp. S79-S86, 2013.

[61] M. S. Parihar and T. Hemnani, "Alzheimer's disease pathogenesis and therapeutic interventions," Journal of Clinical Neuroscience, vol. 11, no. 5, pp. 456-467, 2004.

[62] K. Iqbal and I. Grundke-Iqbal, "Opportunities and challenges in developing Alzheimer disease therapeutics," Acta Neuropathologica, vol. 122, no. 5, pp. 543-549, 2011.

[63] L. D. Morrison, D. D. Smith, and S. J. Kish, "Brain Sadenosylmethionine levels are severely decreased in Alzheimer's disease," Journal of Neurochemistry, vol. 67, no. 3, pp. 1328-1331, 1996.

[64] X.-Q. Liu, X.-Q. Liu, P. Jiang, H. Huang, and Y. Yan, “Plasma levels of endogenous hydrogen sulfide and homocysteine in patients with Alzheimer's disease and vascular dementia and the significance thereof," National Medical Journal of China, vol. 88, no. 32, pp. 2246-2249, 2008.

[65] X.-Q. Tang, X.-T. Shen, Y.-E. Huang et al., "Hydrogen sulfide antagonizes homocysteine-induced neurotoxicity in PC12 cells," Neuroscience Research, vol. 68, no. 3, pp. 241-249, 2010.

[66] Y. Zhang, Z.-H. Tang, Z. Ren et al., "Hydrogen sulfide, the next potent preventive and therapeutic agent in aging and ageassociated disease," Molecular and Cellular Biology, vol. 33, no. 6, pp. 1104-1113, 2013.

[67] Y.-Y. Liu and J.-S. Bian, "Hydrogen sulfide protects amyloid$\beta$ induced cell toxicity in microglia," Journal of Alzheimer's Disease, vol. 22, no. 4, pp. 1189-1200, 2010.

[68] S. M. Schreier, M. K. Muellner, H. Steinkellner et al., "Hydrogen sulfide scavenges the cytotoxic lipid oxidation product 4-HNE," Neurotoxicity Research, vol. 17, no. 3, pp. 249-256, 2010.

[69] Y.-D. Wen, H. Wang, S.-H. Kho et al., "Hydrogen sulfide protects HUVECs against hydrogen peroxide induced mitochondrial dysfunction and oxidative stress," PLoS ONE, vol. 8, no. 2, article e53147, 2013.

[70] D. Giuliani, A. Ottani, D. Zaffe et al., "Hydrogen sulfide slows down progression of experimental Alzheimer's disease by targeting multiple pathophysiological mechanisms," Neurobiology of Learning and Memory, vol. 104, pp. 82-91, 2013.

[71] H.-J. Wei, X. Li, and X.-Q. Tang, "Therapeutic benefits of $\mathrm{H}_{2} \mathrm{~S}$ in Alzheimer's disease," Journal of Clinical Neuroscience, vol. 21, no. 10, pp. 1665-1669, 2014.

[72] R. Obeid, A. McCaddon, and W. Herrmann, "The role of hyperhomocysteinemia and B-vitamin deficiency in neurological and psychiatric diseases," Clinical Chemistry and Laboratory Medicine, vol. 45, no. 12, pp. 1590-1606, 2007.

[73] M. van den Berg, M. S. van der Knaap, G. H. J. Boers, C. D. A. Stehouwer, J. A. Rauwerda, and J. Valk, "Hyperhomocysteinaemia; with reference to its neuroradiological aspects," Neuroradiology, vol. 37, no. 5, pp. 403-411, 1995.

[74] K. Eto, T. Asada, K. Arima, T. Makifuchi, and H. Kimura, "Brain hydrogen sulfide is severely decreased in Alzheimer's disease," Biochemical and Biophysical Research Communications, vol. 293, no. 5, pp. 1485-1488, 2002. 
[75] U. Sen, P. Basu, O. A. Abe et al., "Hydrogen sulfide ameliorates hyperhomocysteinemia-associated chronic renal failure," American Journal of Physiology-Renal Physiology, vol. 297, no. 2, pp. F410-F419, 2009.

[76] S.-K. Yan, T. Chang, H. Wang, L. Wu, R. Wang, and Q. H. Meng, "Effects of hydrogen sulfide on homocysteine-induced oxidative stress in vascular smooth muscle cells," Biochemical and Biophysical Research Communications, vol. 351, no. 2, pp. 485-491, 2006.

[77] H. Lee, E.-J. Lee, Y. S. Song, and E. Kim, "Long-term depressioninducing stimuli promote cleavage of the synaptic adhesion molecule NGL-3 through NMDA receptors, matrix metalloproteinases and presenilin $/ \gamma$-secretase," Philosophical Transactions of the Royal Society of London B: Biological Sciences, vol. 369, no. 1633, Article ID 20130158, 2014.

[78] P. K. Kamat, P. Kyles, A. Kalani, and N. Tyagi, "Hydrogen sulfide ameliorates homocysteine-induced Alzheimer's diseaselike pathology, blood-brain barrier disruption, and synaptic disorder," Molecular Neurobiology, vol. 53, no. 4, pp. 2451-2467, 2016.

[79] X. Xu, C. Liu, Z. Li, and T. Zhang, "Effects of hydrogen sulfide on modulation of theta-gamma coupling in hippocampus in vascular dementia rats," Brain Topography, vol. 28, no. 6, pp. 879-894, 2015.

[80] K. Qu, C. P. L. H. Chen, B. Halliwell, P. K. Moore, and P. T.$\mathrm{H}$. Wong, "Hydrogen sulfide is a mediator of cerebral ischemic damage," Stroke, vol. 37, no. 3, pp. 889-893, 2006.

[81] I. Ishii, N. Akahoshi, H. Yamada, S. Nakano, T. Izumi, and M. Suematsu, "Cystathionine $\gamma$-lyase-deficient mice require dietary cysteine to protect against acute lethal myopathy and oxidative injury," Journal of Biological Chemistry, vol. 285, no. 34, pp. 26358-26368, 2010.

[82] Z. Li, Y. Wang, Y. Xie, Z. Yang, and T. Zhang, "Protective effects of exogenous hydrogen sulfide on neurons of hippocampus in a rat model of brain ischemia," Neurochemical Research, vol. 36, no. 10, pp. 1840-1849, 2011.

[83] X. Wen, D. Qi, Y. Sun et al., " $\mathrm{H}_{2} \mathrm{~S}$ attenuates cognitive deficits through Akt1/JNK3 signaling pathway in ischemic stroke," Behavioural Brain Research, vol. 269, pp. 6-14, 2014.

[84] Z.-L. Chen, W.-M. Yu, and S. Strickland, "Peripheral regeneration," Annual Review of Neuroscience, vol. 30, no. 1, pp. 209-233, 2007.

[85] K. Bhatheja and J. Field, "Schwann cells: origins and role in axonal maintenance and regeneration," The Journal of Biochemistry and Cell Biology, vol. 38, no. 12, pp. 1995-1999, 2006.

[86] W. W. Campbell, "Evaluation and management of peripheral nerve injury," Clinical Neurophysiology, vol. 119, no. 9, pp. 19511965, 2008.

[87] D. Levy, P. Kubes, and D. W. Zochodne, "Delayed peripheral nerve degeneration, regeneration, and pain in mice lacking inducible nitric oxide synthase," Journal of Neuropathology \& Experimental Neurology, vol. 60, no. 5, pp. 411-421, 2001.

[88] S. Rangaraju, D. Hankins, I. Madorsky et al., "Molecular architecture of myelinated peripheral nerves is supported by calorie restriction with aging," Aging Cell, vol. 8, no. 2, pp. 178191, 2009.

[89] H. Rösch, R. Schweigreiter, T. Bonhoeffer, Y.-A. Barde, and M. Korte, "The neurotrophin receptor p75NTR modulates longterm depression and regulates the expression of AMPA receptor subunits in the hippocampus," Proceedings of the National Academy of Sciences of the United States of America, vol. 102, no. 20, pp. 7362-7367, 2005.
[90] G. Dechant and Y.-A. Barde, “The neurotrophin receptor p $75^{\text {NTR }}$ : novel functions and implications for diseases of the nervous system," Nature Neuroscience, vol. 5, no. 11, pp. 11311136, 2002.

[91] J. Scheib and A. Höke, "Advances in peripheral nerve regeneration," Nature Reviews Neurology, vol. 9, no. 12, pp. 668-676, 2013.

[92] X. Fontana, M. Hristova, C. Da Costa et al., "C-Jun in Schwann cells promotes axonal regeneration and motoneuron survival via paracrine signaling," Journal of Cell Biology, vol. 198, no. 1, pp. 127-141, 2012.

[93] H. K. Lee, Y. K. Shin, J. Jung, S.-Y. Seo, S.-Y. Baek, and H. T. Park, "Proteasome inhibition suppresses schwann cell dedifferentiation in vitro and in vivo," Glia, vol. 57, no. 16, pp. 1825-1834, 2009.

[94] J. Jung, W. Cai, S. Y. Jang et al., “Transient lysosomal activation is essential for p75 nerve growth factor receptor expression in myelinated Schwann cells during Wallerian degeneration," Anatomy \& Cell Biology, vol. 44, no. 1, pp. 41-49, 2011.

[95] G. Yang, W. Yang, L. Wu, and R. Wang, " $\mathrm{H}_{2} \mathrm{~S}$, endoplasmic reticulum stress, and apoptosis of insulin-secreting beta cells," Journal of Biological Chemistry, vol. 282, no. 22, pp. 16567-16576, 2007.

[96] R. Wang, "Signaling pathways for the vascular effects of hydrogen sulfide," Current Opinion in Nephrology and Hypertension, vol. 20, no. 2, pp. 107-112, 2011.

[97] H. Kimura, N. Shibuya, and Y. Kimura, "Hydrogen sulfide is a signaling molecule and a cytoprotectant," Antioxidants \& Redox Signaling, vol. 17, no. 1, pp. 45-57, 2012.

[98] N. Krishnan, C. Fu, D. J. Pappin, and N. K. Tonks, " $\mathrm{H}_{2}$ S-induced sulfhydration of the phosphatase PTP1B and its role in the endoplasmic reticulum stress response," Science Signaling, vol. 4, no. 203, article ra86, 2011.

[99] R. D. Di Villa Bianca, R. Sorrentino, P. Maffia et al., "Hydrogen sulfide as a mediator of human corpus cavernosum smoothmuscle relaxation," Proceedings of the National Academy of Sciences of the United States of America, vol. 106, no. 11, pp. 45134518, 2009.

[100] N. Barbera, A. Montana, F. Indorato, N. Arbouche, and G. Romano, "Domino effect: an unusual case of six fatal hydrogen sulfide poisonings in quick succession," Forensic Science International, vol. 260, pp. e7-e10, 2016.

[101] K. R. Olson and N. L. Whitfield, "Hydrogen sulfide and oxygen sensing in the cardiovascular system," Antioxidants \& Redox Signaling, vol. 12, no. 10, pp. 1219-1234, 2010.

[102] T. Chang, A. Untereiner, J. Liu, and L. Wu, "Interaction of methylglyoxal and hydrogen sulfide in rat vascular smooth muscle cells," Antioxidants and Redox Signaling, vol. 12, no. 9, pp. 1093-1100, 2010.

[103] H. Kimura, "Hydrogen sulfide: from brain to gut," Antioxidants and Redox Signaling, vol. 12, no. 9, pp. 1111-1123, 2010.

[104] W.-L. Yin, J.-Q. He, B. Hu, Z.-S. Jiang, and X.-Q. Tang, "Hydrogen sulfide inhibits $\mathrm{MPP}^{+}$-induced apoptosis in PC12 cells," Life Sciences, vol. 85, no. 7-8, pp. 269-275, 2009.

[105] L.-F. Hu, M. Lu, Z.-Y. Wu, P. T.-H. Wong, and J.-S. Bian, "Hydrogen sulfide inhibits rotenone-induced apoptosis via preservation of mitochondrial function," Molecular Pharmacology, vol. 75, no. 1, pp. 27-34, 2009.

[106] Y. Geng, E. Li, Q. Mu et al., "Hydrogen sulfide inhalation decreases early blood-brain barrier permeability and brain edema induced by cardiac arrest and resuscitation," Journal of Perinatology, vol. 35, no. 3, pp. 494-500, 2015. 
[107] K. Kida, E. Marutani, R. K. Nguyen, and F. Ichinose, "Inhaled hydrogen sulfide prevents neuropathic pain after peripheral nerve injury in mice," Nitric Oxide-Biology and Chemistry, vol. 46, pp. 87-92, 2015.

[108] W.-L. Chen, Y.-Y. Niu, W.-Z. Jiang et al., "Neuroprotective effects of hydrogen sulfide and the underlying signaling pathways," Reviews in the Neurosciences, vol. 26, no. 2, pp. 129-142, 2015.

[109] J. L. Wallace and R. Wang, "Hydrogen sulfide-based therapeutics: exploiting a unique but ubiquitous gasotransmitter," Nature Reviews Drug Discovery, vol. 14, no. 5, pp. 329-345, 2015.

[110] S. Fiorucci, S. Orlandi, A. Mencarelli et al., "Enhanced activity of a hydrogen sulphide-releasing derivative of mesalamine (ATB-429) in a mouse model of colitis," British Journal of Pharmacology, vol. 150, no. 8, pp. 996-1002, 2007.

[111] J. L. Wallace, "Hydrogen sulfide-releasing anti-inflammatory drugs," Trends in Pharmacological Sciences, vol. 28, no. 10, pp. 501-505, 2007.

[112] Y.-P. Yu, X.-L. Chi, and L.-J. Liu, "A hypothesis: hydrogen sulfide might be neuroprotective against subarachnoid hemorrhage induced brain injury," The Scientific World Journal, vol. 2014, Article ID 432318, 9 pages, 2014.

[113] Y. Cui, X. Duan, H. Li et al., "Hydrogen sulfide ameliorates early brain injury following subarachnoid hemorrhage in rats," Molecular Neurobiology, 2015.

[114] E. Cadenas and L. Packer, Hydrogen Sulfide in Redox Biology, Academic Press, Elsevier, 2015.

[115] E. Lim, O. Mbowe, A. S. Lee, and J. Davis, "Effect of environmental exposure to hydrogen sulfide on central nervous system and respiratory function: a systematic review of human studies," International Journal of Occupational and Environmental Health, vol. 22, no. 1, pp. 80-90, 2016.

[116] M. Zhang, H. Shan, P. Chang et al., "Hydrogen sulfide offers neuroprotection on traumatic brain injury in parallel with reduced apoptosis and autophagy in mice," PLoS ONE, vol. 9, no. 1, Article ID e87241, 2014. 


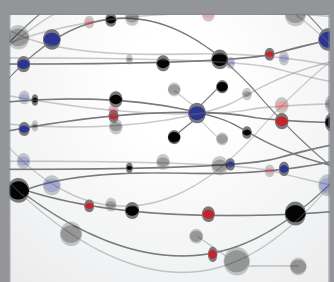

The Scientific World Journal
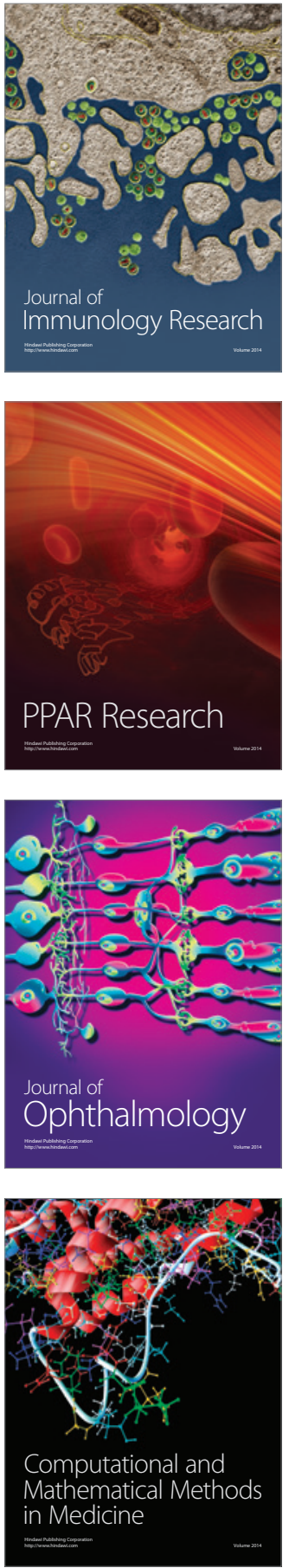

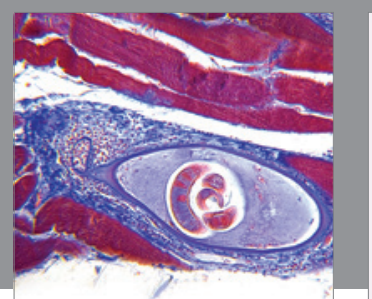

Gastroenterology Research and Practice

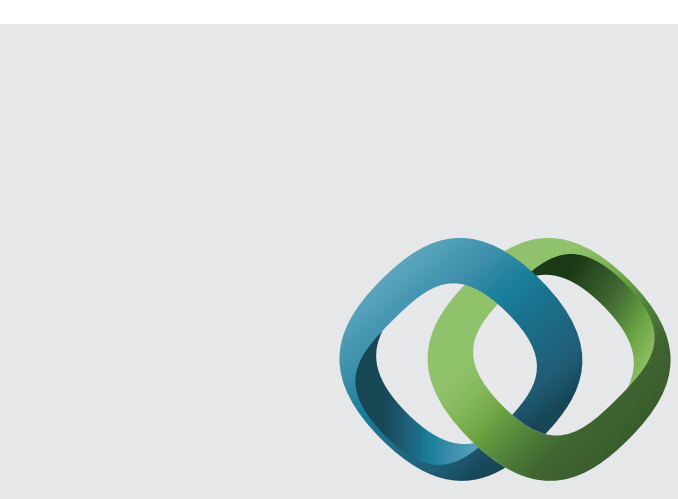

\section{Hindawi}

Submit your manuscripts at

http://www.hindawi.com
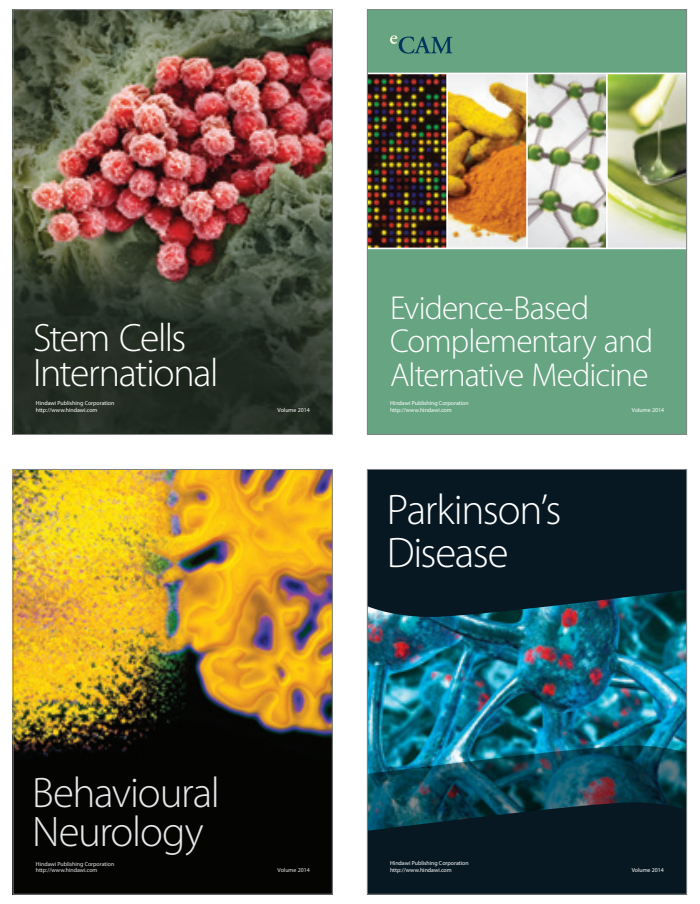
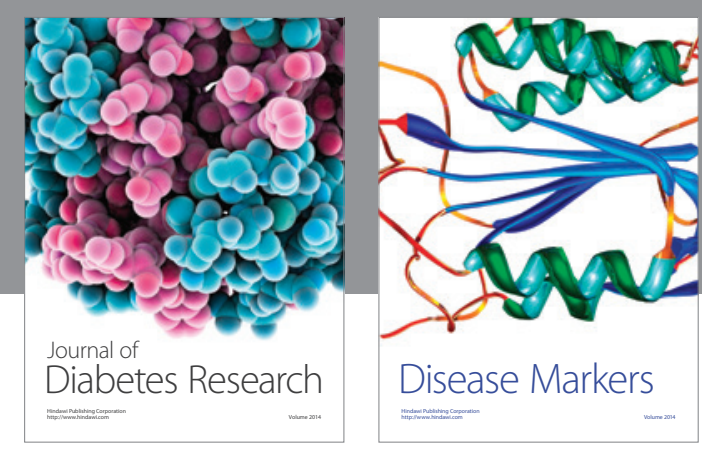

Disease Markers
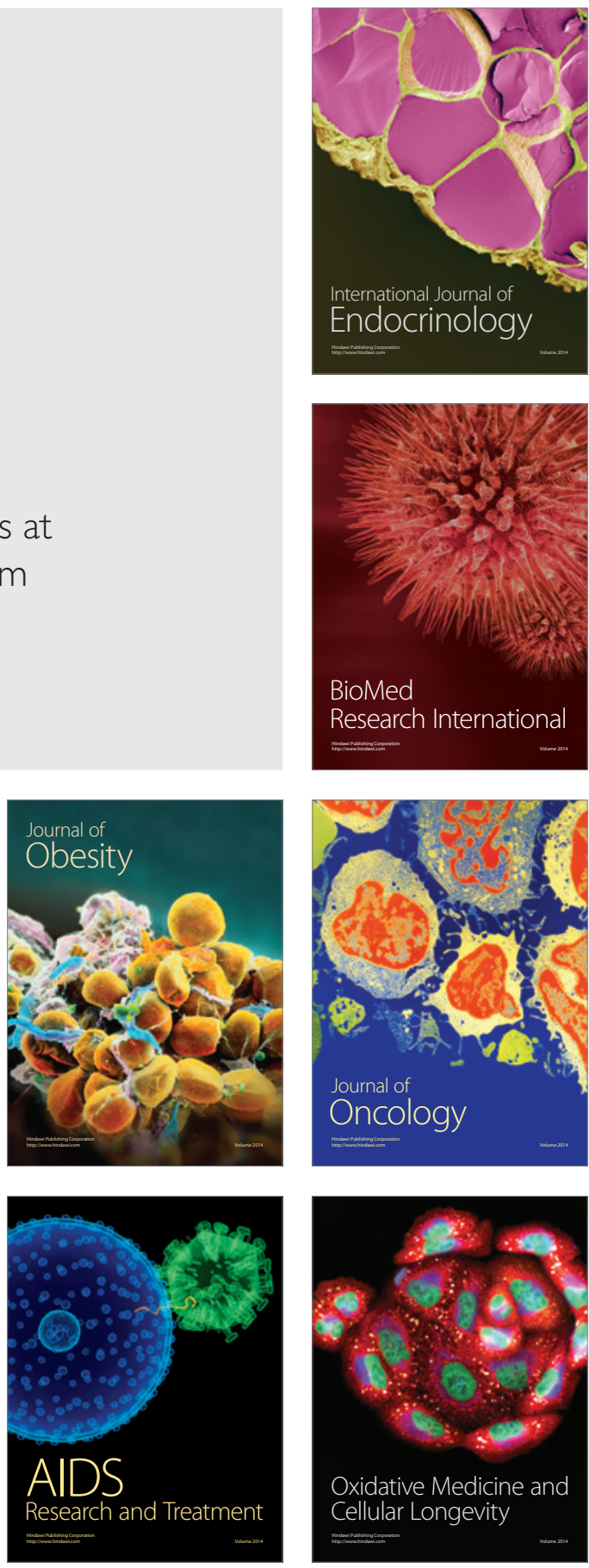